\title{
Analysis of the concentration of selected serological parameters in patients undergoing antibiotic treatment of Lyme disease, and assessment of their potential application in the control of therapy effectiveness - pilot study
}

\author{
Małgorzata Tokarska-Rodak ${ }^{1, A, C-D, F \oplus}$, Hanna Fota-Markowska ${ }^{2,3, A-C, E \oplus}{ }^{\text {, Anna Pańczuk }}{ }^{1, C-D, F \oplus}$, \\ Katarzyna Matuska ${ }^{4, \mathrm{~B}-\mathrm{C}, \mathrm{F} \oplus}$, Marta Zarębska ${ }^{5, \mathrm{~B}, \mathrm{~F} \odot}$ \\ ${ }^{1}$ Faculty of Health Sciences, Pope John Paul II State School of Higher Education in Biała Podlaska, Poland \\ ${ }^{2}$ Department of Infectious Diseases, Medical University, Lublin, Poland \\ ${ }^{3}$ Witold Chodźko Institute of Rural Heath, Lublin, Poland \\ ${ }^{4}$ Department of Microbiological Diagnostics, Clinical Hospital No. 1, Lublin, Poland \\ ${ }^{5}$ Innovation Research Centre, Pope John Paul II State School of Higher Education in Biała Podlaska, Poland \\ $A$ - Research concept and design, B - Collection and/or assembly of data, C - Data analysis and interpretation, \\ $D$ - Writing the article, E-Critical revision of the article, F- Final approval of article
}

\begin{abstract}
Tokarska-Rodak M, Fota-Markowska H, Pańczuk A, Matuska K, Zarębska M. Analysis of the concentration of selected serological parameters in patients undergoing antibiotic treatment of Lyme disease, and assessment of their potential application in the control of therapy effectiveness - pilot study. Ann Agric Environ Med. 2021; 28(4): 605-611. doi: 10.26444/aaem/132786
\end{abstract}

\begin{abstract}
Objective. The aim of the study was to analyze the concentrations of some serological parameters in patients undergoing antibiotic therapy for LD, and to assess the potential use of IgG anti-C6VIsE in the assessment of treatment effectiveness. Materials and method. The study involved 21 patients diagnosed with LD. To determine the levels of anti-C6VlsE IgG, metalloproteinases and cytokines, blood was collected three times: before treatment, immediately after treatment, and 3-4 months after treatment.

Results. Immediately after the antibiotic therapy, all the patients in the study group declared improvement in their health. At 3-4 months post-treatment, 50\% of patients reported recurrence of the disease symptoms. The anti-C6VlsE IgG concentrations at the analyzed time points exhibited varied dynamics: in 15\% of patients, a decrease in the concentration of anti-C6VlsE was observed in the three consecutive serum samples; an increase of anti-C6VIsE IgG was detected in 35\% of cases; in $15 \%$ of the subjects, the concentration of anti-C6VlsE IgG increased immediately after the antibiotic therapy and declined after 3-4 months, whereas a reverse situation was noted in $10 \%$ of the patients.

Conclusions. The presence of high concentrations of anti-C6VlsE IgG is associated with appearance of response to Borreliella spp. infection, which suggests that the parameter can be used in the diagnosis of the active form of borreliosis. However, from a practical point of view, a marker of successful elimination of infection should indicate the effectiveness or failure of antibiotic therapy within a relatively short post-treatment period. The anti-C6VIsE IgG antibodies do not seem to satisfy this provision.
\end{abstract}

\section{Key words}

cytokines, chemokines, metalloproteinases, Lyme borreliosis, Borreliella spp, anti-C6VIsE IgG

\section{INTRODUCTION}

Clinical symptoms of Lyme Disease (LD) can manifest themselves as Early Localized Lyme Disease, Early Disseminated Lyme Disease, or Late Disseminated Lyme Disease. The early form is characterized by the appearance of EM skin lesions in approximately $70 \%$ of patients and/ or flu-like symptoms, such as fatigue, headache, myalgia, arthralgia, and fever. The symptoms of the early disseminated form include multiple EM, acute neurological symptoms, Lyme carditis, borrelial lymphocytoma, and/or systemic symptoms. An untreated infection with Borreliella spp. may

Address for correspondence: Małgorzata Tokarska-Rodak, Faculty of Health Sciences, Pope John Paul II State School of Higher Education in Biała Podlaska, Sidorska 95-97, 21-500 Biała Podlaska, Poland

E-mail: rodak.malgorzata@gmail.com

Received: 25.11.2020; accepted: 25.01.2021; first published: 11.02.2021 manifest itself as Lyme arthritis or Lyme carditis several months or years after the infection. Clinical symptoms in the nervous system (encephalitis, polyneuropathy) and skin (acrodermatitis chronica atrophicans-ACA, lymphocytoma) may additionally be observed $[1,2,3,4]$. There is also a form referred to as Post-Treatment Lyme Disease Syndrome (PTLDS), which develops when antibiotic therapy does not bring expected clinical results. There are various criteria of diagnosis of PTLDS, e.g. fatigue, extensive musculoskeletal pain, and cognitive difficulties resulting in debilitation of professional, educational, personal, or social activities [1].

The diagnosis of LD is based on the presence of at least one clinical symptom: EM, Borrelial lymphoma, ACA, or a complex of symptoms related to Lyme carditis, Lyme arthritis, neuroborreliosis [3]. Another element of LD diagnostics, with the exception of early EM skin lesions, involves two-stage serological tests aimed at detection of specific anti-Borreliella 
antibodies $[1,2]$. Their absence in patients with suspected Lyme disease usually excludes the diagnosis [3]. Specific antiBorreliella antibodies can also be detected in healthy subjects, i.e. at a level of $12 \%$ of the population (blood donors) and approximately $40 \%$ in groups with an increased occupational risk related to exposure to tick bites. The presence of antibodies without clinical symptoms cannot be an indication for treatment [4]. In clinical practice, etiotropic antibiotic therapy is the standard of therapeutic management. The evaluation of treatment effects is based on subjective improvement, inhibition or deceleration of disease progression, or disappearance of clinical symptoms. Specific anti-Borreliella antibodies may persist after treatment: IgM for a few years and IgG for many years, often with a tendency for their levels to decline slowly. Their presence does imply failure of treatment $[3,4]$. In patients with sero-conversion, the conventional diagnostic scheme is unable to distinguish between a past and an active infection, which is a clinical and diagnostic problem [1].

It is not recommended that the treatment of Lyme disease should be based on long-term antibiotic therapy, multiple repetitions of the therapy, and combined treatment with several antibiotics. The treatment should be assessed based on the dynamics of the clinical picture $[2,3]$. Some LD patients respond well to antibiotic therapy, which leads to full recovery. In contrast, other patients do not respond to the implemented treatment and the clinical symptoms of the disease are not eliminated [1].

One of the problems in Lyme disease is the lack of a reliable marker with high sensitivity and specificity for evaluation of the effectiveness of antibiotic therapy administered to patients. A marker that could be used for such a control should appear instantaneously in patient's serum after Borreliella infection, and disappear immediately after successful treatment of the disease [5]. Various studies have shown that IgG anti-C6VlsE antibodies appear relatively quickly in early and late Lyme disease $[6,7$, and disappear relatively quickly after antibiotic therapy $[8,9]$.

The intensity of the immune response in LD against Borreliella spirochetes depends on many coexisting factors. $B$. burgdorferi contains ligands that activate different tolllike receptors (TLRs: e.g. TLR2, TLR5) and this signalling pathway leads to the activation of pro-inflammatory cytokines [10]. Macrophage Receptor with Collagenous Structure (MARCO) does mediate B. burgdorferi phagocytosis. As reported by Petnicki-Ocwieja et al.: 'MARCO was significantly up-regulated on $B$. burgdorferi stimulation, and the up-regulation of MARCO was dependent on MyD88, and MARCO deficient macrophage showed a decrease in the phagocytosis of B. burgdorfer' [11]. Spirochetes activate proteolytic enzymes, including matrix metallproteinases (MMPs), which are involved in the degradation of protein components of the extracellular matrix and in degenerative processes which, in turn, induce activation or inactivation of cytokines and chemokines $[12,13,14,15]$.

\section{OBJECTIVE}

The aim of the study was to analyze the concentrations of some serological parameters in patients undergoing antibiotic therapy for Lyme disease, and to assess the potential use of IgG anti-C6VlsE in the assessment of treatment effectiveness. The study is a pilot research project.

\section{MATERIALS AND METHOD}

Study group. The study involved 21 patients (14 females and 7 males) diagnosed with Lyme disease and treated at the Clinic of Infectious Diseases at the Medical University in Lublin, Poland. The age of the patients ranged from 2175 years (mean age 56, SD 13.6). Diagnosis was based on medical history, physical examination, clinical picture, and serological tests for Lyme disease, in accordance with the relevant recommendations [3].

In the patients with clinical symptoms of Lyme disease (21 subjects), antibodies against specific Borreliella antigen proteins were detected: IgM/IgG in $8 / 21$ patients (38\%) and IgG in $13 / 21$ patients (62\%). In the IgM class, antibodies against OspC were detected most commonly (38\%), while other antibodies were rarely found (p17-5\%, p31-5\%, p39$5 \%)$. In the IgG class, antibodies against VlsE B. burgdorferi (90\%), VlsE B. afzelii (86\%), VlsE B. garinii (81\%), OspC (67\%) were detected most commonly, while other antibodies were rarely found: p39 (33\%), p83 (33\%), p58 (28\%), p19 (24\%), p18 (24\%), p21 (19\%), LBa (14\%), LBb (9\%), p20 (9\%).

The group comprised patients with predominant articular symptoms, such as arthralgia and/or arthritis, who received etiotropic parenteral antibiotic therapy. They were treated with Ceftriaxonum (2x1g iv for 28 days).

To determine the levels of anti-C6VlsE IgG, metalloproteinases, cytokines, and chemokines, blood was collected three times: before treatment (sample I), immediately after treatment (sample II), and 3-4 months after treatment (sample III). The results were compared in chosen time points (Internal quality).

The project was authorized by the Bioethical Committee of Medical University in Lublin (Permission No. KE0254/27/2016).

Serological assays. The Lyme Trace Elisa (Euroimmun, Germany) assay based on a mixture of recombinant B. burgdorferi s.s and B. afzelii VlsE was used to quantify the concentration of anti-B. burgdorferi C6VlsE IgG. As specified by the manufacturer of the assay, the titer of antiVlsE IgG antibodies in most cases decreases after effective antibiotic therapy. The lower limit of sensitivity of the assay was $0.6 \mathrm{RU} / \mathrm{ml}$, cut-off $20.0 \mathrm{RU} / \mathrm{ml}$.

To identify potential co-infections with pathogens other than Borreliella spp. transmitted by ticks, tests detecting the presence of anti-Anaplasma phagocytophilum IgG in serum were carried out (IFA IgG Antibody Kit; Fuller Laboratories, USA). Solid-phase antigens containing fixed THP-1 cells were infected with $A$. phagocytophilum. The patient sera were diluted to 1:80. A positive reaction was seen as sharply defined green fluorescent inclusions in the cytoplasm of infected cells. The fluorescence intensity of the positive control diluted to 1:640 was considered as the cut-off value. The tests may give false positive results due to possible cross-reactions in the case of E. chaffeensis, EBV virus, and rickettsial infections and in the presence of anti-leukocyte autoantibodies.

The concentration of MMP-2 in the serum was determined (ELISA, R\&D). Minimum detectable dose (MDD) of MMP-2 ranged from $0.014-0.082 \mathrm{ng} / \mathrm{ml}$.

The concentration of MMP-9 in the serum was determined (EISA, R\&D). The minimum detectable dose (MDD) of human MMP-9 is typically less than $0.156 \mathrm{ng} / \mathrm{ml}$. 
The concentration of IL-2, IL-4, IL-6, IL-10, IL-17A, IFN-g, TNF- $\alpha$ in the serum was determined (Human Cytometric Bead Array Kit Th1/Th2/Th17; Becton Dickinson; BD).

The concentration of IL-8 (CXCL-8), CCL5 (RANTES, Regulated on Activation, Normal T-cell Expressed and Secreted), monokine induced by gamma interferon (CXCL9/MIG), monocyte chemoattractant protein-1 (CCL-2/MCP1), and interferon gamma induced protein-10 (CXCL-10/ IP-10) in the serum was determined (Human Chemokine I Cytometric Bead Array Kit; Becton Dickinson; BD). Equipment: FACSCanto ${ }^{\mathrm{TM}}$ II cytometer and FCAP Array ${ }^{\mathrm{TM}}$ Software Version 3.0 (Becton Dickinson; BD).

Data were analyzed statistically using the Statistica v.10 programme. The Mann-Whitney U test and the KruskalWallis test were employed to determine the statistical significance of the results. Values of $\mathrm{p}<0.05$ were considered statistically significant.

\section{RESULTS}

Assessment of the effectiveness of the antibiotic treatment of Lyme disease in patients based on medical history. During the antibiotic therapy (Ceftriaxonum), one of the 21 patients developed allergy symptoms to the drug used; therefore, 20 patients were qualified for further analyses (100\%).

Immediately after the 28-day antibiotic therapy, all the patients in the study group (20 subjects; $100 \%)$ declared improvement in their health. At 3-4 months post-treatment, $10 / 20$ patients $(50 \%)$ reported good health and resolution of the Lyme disease symptoms during a follow-up visit. The other $10 / 20$ patients (50\%) reported recurrence of the disease symptoms.

Assessment of the effectiveness of the antibiotic treatment of Lyme disease in patients based on the level of anti-B. burgdorferi C6VlsE IgG. The concentration of anti-B. burgdorferi C6VlsE IgG was measured three times in 20 patients treated for the diagnosed Lyme disease. The first assay (I) was performed before administration of the Ceftriaxonum antibiotic therapy, the second test (II) was carried out after the 28-day treatment, and the third analysis (III) was performed 3-4 months after the treatment (Tab. 1). The anti-C6VlsE IgG concentrations at the analyzed time points exhibited varied dynamics.

Figures $1 \mathrm{~A}$ and $1 \mathrm{~B}$ show the dynamics of changes in the anti-C6VlsE IgG concentration in patients that declared improvement in their health immediately after the treatment and recurrence of disease symptoms at 3-4 months after the therapy. Figures $2 \mathrm{~A}$ and $2 \mathrm{~B}$ present the dynamics of changes in the anti-C6VlsE IgG concentration in patients declaring improvement in their health status immediately after the therapy and at 3-4 months post treatment.

In $15 \%(3 / 20)$ of the patients, a systematic decrease in the concentration of anti-C6VlsE IgG was observed in the three consecutive serum samples, however, the clinical symptoms of Lyme disease were resolved in two patients.

An increase in the concentration of anti-C6VlsE IgG in the three consecutive serum samples was detected in 7/20 cases (35\%), with only three patients in this group reporting resolution of the disease symptoms. In $15 \%(3 / 20)$ of the subjects, the concentration of anti-C6VlsE IgG increased
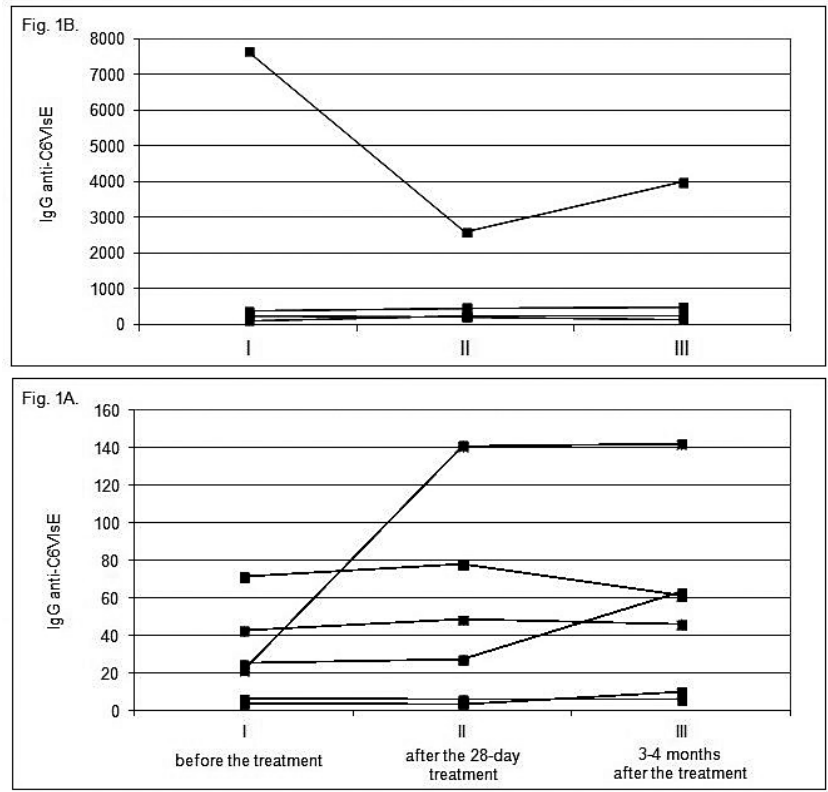

Figure 1A, 1B. Dynamics of changes in the anti-C6VlsE IgG concentration in patients who declared improvement in their health immediately after treatment, and recurrence of disease symptoms at 3-4 months after treatment
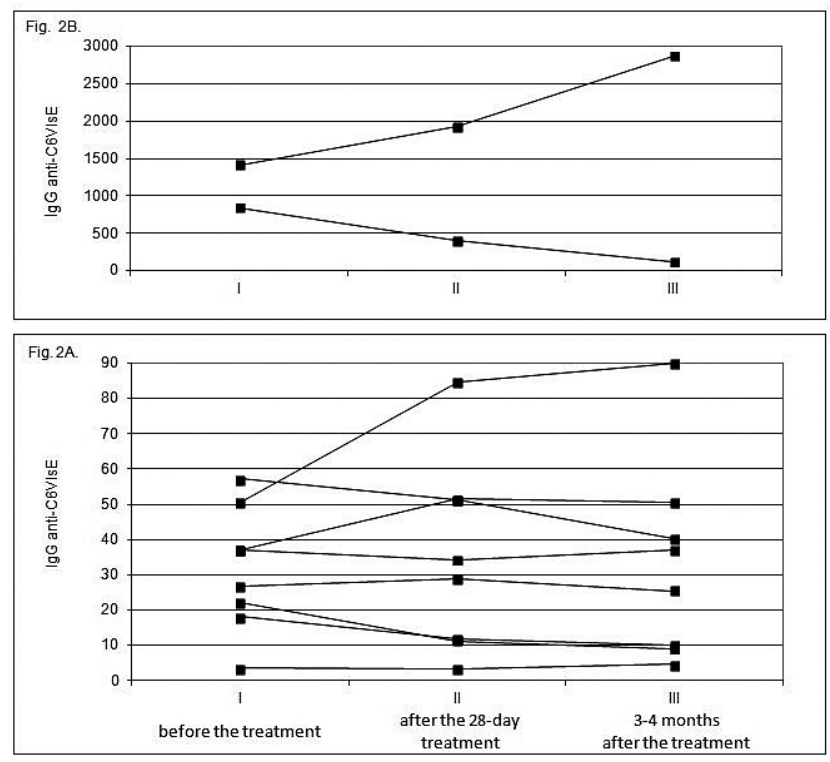

Figure 2A, 2B. Dynamics of changes in the anti-C6VIsE IgG concentration in patients declaring improvement in their health status immediately after treatment, and at 3-4 months post-treatment

immediately after the antibiotic therapy and declined after 3-4 months, whereas a reverse situation (a decrease in the concentration directly after the antibiotic therapy and an increase after 3-4 months) was noted in $10 \%(2 / 20)$ of the patients. Resolution of the clinical symptoms of Lyme disease was reported by one patient from each of the two groups. The concentration of anti-C6VlsE IgG was below 20RU/ml (cut off) in $25 \%$ of the patients (5) with Lyme disease symptoms, and the symptoms of the disease resolved after the treatment in three subjects.

In total, $10 / 20$ patients in the study group (50\%) reported resolution of clinical Lyme disease symptoms, mainly articular symptoms such as arthralgia and/or arthritis (Tab. 1). 
Table 1. Concentration of anti-B. burgdorferi C6VlsE IgG in patients treated for diagnosed Lyme disease

\begin{tabular}{|c|c|c|c|c|c|c|c|c|}
\hline \multirow[t]{2}{*}{ Anti-C6VlsE IgG concentrations } & \multirow{2}{*}{$\begin{array}{l}\text { Patients } \\
\mathrm{N}=20(100 \%)\end{array}$} & \multicolumn{5}{|c|}{ IgG anty-C6VlsE [RU/ml] } & $\begin{array}{l}\text { Elimination } \\
\text { of symptoms }\end{array}$ & $\begin{array}{l}\text { Recurrence } \\
\text { of symptoms }\end{array}$ \\
\hline & & Assay number & mean value & $\min$ & $\max$ & SD & $\mathrm{N}=$ & \\
\hline \multirow{3}{*}{ A decrease in the three consecutive serum samples } & \multirow{3}{*}{$3(15 \%)$} & 1 & 378.4 & 57.3 & 840.0 & 409.8 & \multirow{3}{*}{$2(10 \%)$} & \multirow{3}{*}{$1(5 \%)$} \\
\hline & & II & 220.8 & 51.4 & 400.0 & 174.5 & & \\
\hline & & III & 65.0 & 40.4 & 144.0 & 52.9 & & \\
\hline \multirow{3}{*}{ An increase in the three consecutive serum samples } & \multirow{3}{*}{$7(35 \%)$} & 1 & 288.9 & 21.4 & 1417.3 & 512.0 & \multirow{3}{*}{$3(15 \%)$} & \multirow{3}{*}{$4(20 \%)$} \\
\hline & & II & 415.4 & 27.5 & 1923.9 & 681.0 & & \\
\hline & & III & 560.1 & 50.6 & 2870.0 & 1029.6 & & \\
\hline \multirow{3}{*}{$\begin{array}{l}\text { An increase immediately after the antibiotic therapy and } \\
\text { decline after 3-4 months }\end{array}$} & \multirow{3}{*}{$3(15 \%)$} & 1 & 46.9 & 26.6 & 71.5 & 22.7 & \multirow{3}{*}{$1(5 \%)$} & \multirow{3}{*}{$2(10 \%)$} \\
\hline & & II & 51.8 & 29.0 & 77.9 & 24.6 & & \\
\hline & & III & 44.3 & 25.5 & 61.3 & 17.9 & & \\
\hline \multirow{3}{*}{$\begin{array}{l}\text { A decrease immediately after the antibiotic therapy and } \\
\text { increase after 3-4 months }\end{array}$} & \multirow{3}{*}{$2(10 \%)$} & 1 & 3848.1 & 37.2 & 7659.0 & 5389.4 & \multirow{3}{*}{$1(5 \%)$} & \multirow{3}{*}{$1(5 \%)$} \\
\hline & & II & 1317.1 & 34.2 & 2600.0 & 1814.2 & & \\
\hline & & III & 2018.5 & 37.0 & 4000.0 & 2802.2 & & \\
\hline \multirow{3}{*}{$<20 \mathrm{RU} / \mathrm{ml}$ (cut off) } & \multirow{3}{*}{$5(25 \%)$} & 1 & 10.9 & 3.5 & 22.3 & 8.6 & \multirow{3}{*}{$3(15 \%)$} & \multirow{3}{*}{$2(10 \%)$} \\
\hline & & II & 7.3 & 3.3 & 11.9 & 4.0 & & \\
\hline & & III & 8.8 & 4.7 & 11.9 & 3.1 & & \\
\hline
\end{tabular}

I- before the treatment; II - after the 28-day treatment; III - 3-4 months after the treatment

Co-presence of anti-A. phagocytophilum antibodies. Anti-A. phagocytophilum IgG antibodies were detected in seven of the 20 patients with Lyme disease (35\%). Two of them $(2 / 7)$ reported permanent improvement in their health after the antibiotic therapy, but the symptoms recurred in $5 / 7$ patients at 3-4 months post-treatment. In $1 / 7$ of the patients, a systematic decrease in the concentration of antiC6VlsE IgG was observed in the three consecutive serum samples. An increase in the concentration of anti-C6VlsE IgG in the three consecutive serum samples was detected in $3 / 7$ cases, with only one patient in this group reporting resolution of the disease symptoms. In $2 / 7$ of the subjects, the concentration of anti-C6VlsE IgG increased immediately after the antibiotic therapy and declined after 3-4 months. Resolution of the clinical symptoms of Lyme disease was reported by one patient. In 1/7 of the patients with Lyme disease symptoms the concentration of anti-C6VlsE IgG was below 20RU/ml (cut off).

There were no differences in the concentrations of metalloproteinases, chemokines and cytokines in patients with existing anti- $A$. phagocytophilum and anti- $B$. burgdorferi antibodies compared to patients with anti-B. burgdorferi antibodies.

Dynamics of changes in the concentrations of selected serological parameters in patients treated for Lyme disease. The concentrations of selected metalloproteinases, chemokines, and cytokines were determined three times in the samples from the 20 patients treated for the diagnosed Lyme disease. Samples collected at the same time points as those described above for anti-B. burgdorferi C6VlsE IgG were analyzed (Tab. 2).

Table 2. Concentrations of selected metalloproteinases, and chemokines in patients treated for diagnosed Lyme disease

\begin{tabular}{|c|c|c|c|c|c|c|c|c|c|c|c|c|c|}
\hline \multirow{3}{*}{$\begin{array}{l}\text { Patients } \\
\mathrm{N}=20\end{array}$} & \multicolumn{12}{|c|}{ Parameters } & \multirow{3}{*}{$\begin{array}{l}\text { Declared final health status } \\
\text { after 3-4 months }\end{array}$} \\
\hline & \multicolumn{4}{|c|}{$(\mathrm{ng} / \mathrm{ml})$} & \multicolumn{8}{|c|}{$(\mathrm{pg} / \mathrm{ml})$} & \\
\hline & MMP-2 & SD & MMP-9 & SD & IP-10 & SD & MCP-1 & SD & CXCL-9 & SD & CCL-5 & SD & \\
\hline $\begin{array}{l}\text { Before } \\
\text { treatment }\end{array}$ & 188.1 & 47.3 & 634.3 & 297.4 & 217.5 & 129.0 & 123.6 & 36.4 & 93.5 & 101.3 & 11403.4 & 3452.2 & $\begin{array}{l}\text { Elimination of symptoms } \\
\qquad \mathrm{N}=10\end{array}$ \\
\hline \multirow{3}{*}{$\begin{array}{l}\text { After 28-day } \\
\text { treatment }\end{array}$} & 219.7 & 87.4 & 647.3 & 239.8 & $132.7 *$ & 48.1 & 165.8 & 143.0 & 48.8 & 28.0 & 13535.2 & 1882.3 & $\begin{array}{l}\text { Recurrence of symptoms } \\
\qquad \mathrm{N}=10\end{array}$ \\
\hline & 224.8 & 43.7 & 576.1 & 273.9 & $330.4^{*}$ & 247.7 & 133.2 & 26.5 & 106.1 & 87.3 & 12698.8 & 4343.7 & $\begin{array}{l}\text { Elimination of symptoms } \\
\qquad \mathrm{N}=10\end{array}$ \\
\hline & 221.8 & 70.7 & 615.3 & 251.3 & 226.8 & 197.5 & 150.3 & 104.0 & 76.1 & 68.4 & 13136.9 & 3231.9 & $\begin{array}{l}\text { All patients } \\
\quad \mathrm{N}=20\end{array}$ \\
\hline \multirow[t]{2}{*}{$\begin{array}{l}\text { 3-4 months } \\
\text { after treatment }\end{array}$} & 223.8 & 104.4 & 633.9 & 254.7 & 214.3 & 77.4 & 132.4 & 50.7 & 95.2 & 83.4 & 14146.7 & 1460.7 & $\begin{array}{l}\text { Elimination of symptoms } \\
\qquad \mathrm{N}=10\end{array}$ \\
\hline & 228.3 & 107.9 & 611.7 & 262.1 & 173.4 & 77.5 & 212.7 & 232.8 & 73.0 & 59.8 & 13993.1 & 1797.7 & $\begin{array}{l}\text { All patients } \\
\qquad \mathrm{N}=20\end{array}$ \\
\hline
\end{tabular}

${ }^{*} \mathrm{p}=0.01$ 
It was found that the IP-10 levels in the patients declaring health improvement were higher at each time point than in those reporting no improvement. Immediately after the treatment, the mean concentration of IP-10 (interferon gamma-induced protein-10) in the patients with improvement in their health was significantly higher $(330.4 \mathrm{pg} / \mathrm{ml} ; \mathrm{p}=0.01)$ than in the subjects with recurrence of the symptoms (132.7 pg/ml).

The concentration of MCP-1 and IL- 8 at 3-4 months after the treatment was higher in the patients declaring recurrence of the disease symptoms $(269.0 \mathrm{pg} / \mathrm{ml} ; 29.3 \mathrm{pg} / \mathrm{ml}$, respectively), compared with those who indicated effectiveness of the treatment $(132.4 \mathrm{pg} / \mathrm{ml} ; 21.7 \mathrm{pg} / \mathrm{ml}$, respectively); however, the differences were not statistically significant (Tab. 2, Tab. 3).

\section{DISCUSSION}

The diagnosis of Lyme disease is based on recognition of specific clinical symptoms in the patient and must be confirmed by detection of antibodies against specific Borreliella antigen proteins. As specified by the recommendations for serological diagnosis of Lyme disease, serological tests do not have to be performed only in the case of such skin lesions as erythema migrans, as their occurrence indicates the infection explicitly $[3,4]$. IgM/IgG anti-Borreliella antibodies determined with ELISA and Western blots should not be used as indicators of the effectiveness of Lyme disease treatment, as the therapy efficacy should be assessed taking in consideration only the resolution of the clinical symptoms of the disease [3]. As shown by the data collected from the interviewed patients, all respondents (100\%) declared improvement in their health status at 28 days of the antibiotic therapy, whereas half of the group (50\%) reported good health and resolution of the Lyme disease symptoms 3-4 months post- treatment. The other patients (50\%) reported recurrence of the clinical symptoms of the disease. It is estimated that $10-15 \%$ of patients in North America develop post-treatment symptoms despite the borreliosis treatment [1]. A diagnostically useful measurable marker for determination of the level of anti-B. burgdorferi immune response in relation to the implemented treatment and its effectiveness or ineffectiveness has therefore been sought for many years.

In 15 patients with clinical symptoms of Lyme disease undergoing treatment, Marangoni et al. analyzed the presence of anti-VlsE/C6 IgG every 30 days from the initiation of antibiotic therapy. After 1-6 months, remission of symptoms and absence of anti-VlsE/C6 IgG antibodies were reported in all patients [8]. A study conducted by Philipp et al. demonstrated a total decrease in anti-VlsE/C6 IgG in $59 \%$ of patients undergoing antibiotic therapy for Lyme disease at 4-15 months after the treatment, and a 4 -fold decrease in the level of the antibodies in $32.4 \%$ of patients. As shown by some investigations, a temporary increase in anti-VlsE/C6 IgG followed by a decrease in their titer can be observed in some patients [16]. These studies demonstrated that the titer of the anti-VlsE IgG antibodies decreased in most cases after effective antibiotic therapy. However, no such clear trend was found in the present study. Variable dynamics of the anti-C6VlsE IgG concentrations were observed at the analyzed time points.

A decrease in the anti-C6VlsE IgG concentration in three consecutive serum samples was found in $15 \%$ of the cases. In another $15 \%$ of the patients, the concentration increased after the antibiotic therapy and decreased at 3-4 months post treatment. Thus, the anti-C6VlsE IgG concentration was finally reduced in $30 \%$ of the patients, but only half of them declared resolution of clinical symptoms. In $45 \%$ of the patients, an increased concentration of anti-C6VlsE IgG was detected at 3-4 months post-treatment. Nevertheless, more than half of the subjects declared improvement in their health and resolution of the symptoms of Lyme disease. It cannot be ruled out that if the anti-C6VlsE IgG concentration had been assessed at longer post-treatment intervals, the downward trend would have been more evident. However, from a practical point of view, a marker of successful elimination of infection should indicate the effectiveness or failure of antibiotic therapy within a relatively short post-treatment period, hence the choice of the above-described time points of collection of samples for the analyses.

The usefulness of anti-VlsE/C6 IgG in patients with postLyme syndrome was analyzed by Fleming et al. However,

Table 3. Concentrations of selected cytokines in patients treated for diagnosed Lyme disease

\begin{tabular}{|c|c|c|c|c|c|c|c|c|c|c|c|c|c|c|c|c|c|}
\hline \multirow{2}{*}{$\begin{array}{l}\text { Patients } \\
\mathrm{N}=20\end{array}$} & \multicolumn{16}{|c|}{ Parameters (pg/ml) } & \multirow{2}{*}{$\begin{array}{l}\text { Declared final health status } \\
\text { after 3-4 months }\end{array}$} \\
\hline & IL-8 & SD & IL-17A & SD & $\mathrm{INF} \gamma$ & SD & TNFa & SD & $\mathrm{IL}-10$ & SD & IL-6 & SD & IL-4 & SD & IL-2 & SD & \\
\hline \multirow{3}{*}{$\begin{array}{l}\text { Before } \\
\text { treatment }\end{array}$} & 20.0 & 11.1 & 0.2 & 0.7 & 0.0 & 0.0 & 0.0 & 0.0 & 0.02 & 0.05 & 0.4 & 0.4 & 0.2 & 0.7 & 0.07 & 0.16 & $\begin{array}{l}\text { Recurrence of symptoms } \\
\qquad \mathrm{N}=10\end{array}$ \\
\hline & 19.8 & 17.3 & 0.0 & 0.0 & 0.2 & 0.7 & 7.8 & 24.8 & 1.5 & 4.7 & 6.6 & 14.0 & 1.6 & 4.5 & 4.6 & 14.81 & $\begin{array}{l}\text { Elimination of symptoms } \\
\qquad \mathrm{N}=10\end{array}$ \\
\hline & 19.9 & 22.0 & 0.12 & 0.5 & 0.11 & 0.5 & 3.7 & 17.1 & 0.7 & 3.2 & 3.3 & 9.9 & 0.9 & 3.1 & 2.2 & 10.2 & $\begin{array}{l}\text { All patients } \\
\quad \mathrm{N}=20\end{array}$ \\
\hline \multirow{3}{*}{$\begin{array}{l}\text { After 28-day } \\
\text { treatment }\end{array}$} & 24.8 & 22.4 & 0.3 & 1.1 & 0.1 & 0.3 & 0.0 & 0.0 & 0.0 & 0.0 & 0.3 & 0.3 & 0,2 & 0.5 & 0.2 & 0.39 & $\begin{array}{l}\text { Recurrence of symptoms } \\
\qquad \mathrm{N}=10\end{array}$ \\
\hline & 19.6 & 12.4 & 0.00 & 0.0 & 0.0 & 0.0 & 7.5 & 24.0 & 1.7 & 3.6 & 3.5 & 5.1 & 1.5 & 4.6 & 5.3 & 16.56 & $\begin{array}{l}\text { Elimination of symptoms } \\
\qquad \mathrm{N}=10\end{array}$ \\
\hline & 22.3 & 18.1 & 0.2 & 0.8 & 0.06 & 0.2 & 3.6 & 16.5 & 0.8 & 2.5 & 1.8 & 3.8 & 0.8 & 3.2 & 2.6 & 11.41 & $\begin{array}{l}\text { All patients } \\
\qquad \mathrm{N}=20\end{array}$ \\
\hline \multirow{3}{*}{$\begin{array}{l}3-4 \text { months } \\
\text { after } \\
\text { treatment }\end{array}$} & 29.3 & 45.2 & 0.0 & 0.0 & 0.01 & 0.04 & 1.3 & 4.2 & 0.0 & 0.0 & 0.8 & 1.0 & 0.4 & 1.2 & 2.3 & 5.39 & $\begin{array}{l}\text { Recurrence of symptoms } \\
\qquad \mathrm{N}=10\end{array}$ \\
\hline & 21.7 & 18.9 & 0.06 & 0.1 & 0.0 & 0.0 & 0.0 & 0.0 & 0.0 & 0.0 & 0.8 & 0.9 & 0.0 & 0.0 & 0.1 & 0.31 & $\begin{array}{l}\text { Elimination of symptoms } \\
\qquad \mathrm{N}=10\end{array}$ \\
\hline & 26.1 & 36.0 & 0.02 & 0.1 & 0.01 & 0.03 & 0.8 & 3.2 & 0.0 & 0.0 & 0.8 & 0.9 & 0.2 & 0.9 & 1.4 & 4.19 & $\begin{array}{l}\text { All patients } \\
\mathrm{N}=20\end{array}$ \\
\hline
\end{tabular}


these antibodies in the studied group of patients had lower titers than in patients with active Lyme disease. There was no correlation in the decrease in the anti-VlsE/C6 IgG levels with the treatment applied and resolution of clinical symptoms of the disease [9]. Research shows that C6/VlsE is successfully used in the diagnosis of the active form Lyme borreliosis [17].

An important role in the inflammatory response to Borreliella infection is played by pro- and anti-inflammatory cytokines and chemokines, factors important in the development $B$. burgdorferi-induced Lyme arthritis $[18,19$, 20]. As reported by Sulka et. al., in the synovial fluid, the levels of IL- 6 , IL-8, 10, TNF- $\alpha$, IFN- $\gamma$ and Th1, Th2, and Th17 mediators were greater in the patients with refractory arthritis than in the patients with responsive arthritis. The levels of cytokine and chemokine in serum were lower than in synovial fluid, and the values were similar in the responsive and refractory groups. The only serum levels of IL-4 in the refractory group was significantly higher [13]. Analysis of peripheral blood mononuclear cells (PBMCs) from patients with Lyme arthritis showed, that $B$. burgdorferi can induce the production of chemokines e.g. CCL2, CXCL9, and CXCL10 [16]. Research conducted by Strle et al. in the patients with Lyme arthritis, revealed that the innate inflammatory responses and $\mathrm{TH} 1$ responses were concentrated in synovial fluid. The levels of IFN- $\gamma$-inducible chemokines CXCL9 and CXCL10, were higher in synovial fluid compared with serum [14].

However, there were no statistically significant differences in the concentrations of TNF- $\alpha$, IFN- $\gamma$, IL-2, IL-4, IL-6, IL-8, IL-10, and IL-17 in the Lyme disease patients before and after treatment. A possible role in assessment of the dynamics of the disease process may be ascribed to IP-10, the concentration of which was significantly higher in the patients who declared resolution of the disease symptoms immediately after the treatment $(330.4 \mathrm{pg} / \mathrm{ml})$, compared with those who did not report improvement in their health (132.7 pg/ml).

The role of IP-10 in the clinical course of Lyme arthritis has not been established so far; therefore, this assumption should be verified in a larger group of patients qualified for Lyme disease treatment. Leukocytes, neutrophils, eosinophils, monocytes, and endothelial cells are able to secrete IP-10, which influences various biological functions and chemotactic activity, e.g. the course of infectious diseases. This chemokine has been shown to be important for the course of bacterial (Chlamydia, Mycoplasma, L. pneumophila, H. pylori) and fungal (C. albicans) infections [21]. IP-10 is a chemokine able to regulate inflammation, it can induce integrin activation and mediate chemotaxis. IP-10 is secreted by several cell types: e.g. T lymphocytes, monocytes, fibroblasts and keratinocytes. Research shows, that patients with confirmed neuroborreliosis had significantly higher levels of IP-10 in the cerebrospinal fluid compared to the non- neuroborreliosis group and the control group [22]. In Lyme arthritis, the infiltration of inflammatory cells is related with accumulation of neutrophil-activating protein A, IFN- $\gamma$, IP-10 and others, in synovial fluid [23].

Various investigations confirm the possibility of simultaneous infection with different pathogens transmitted by ticks $[24,25]$. As reported by Dunaj et al., co-infection with $B$. burgdorferi s.l. and A. phagocytophilum was diagnosed in $4.2 \%$ of patients [26]. In turn, research conducted by
Moniuszko showed co-infections with Borreliella spirochetes (formerly Borrelia burgdorferi s.l.) (27\%), A. phagocytophilum (10.9\%), and Babesia spp. (0.9\%) in patients with TBE [27]. The present study demonstrated co-infection with Borreliella and A. phagocytophilum in $35 \%$ of the patients $(7 / 20)$. Concurrently, $5 / 7$ subjects with anti- $A$. phagocytophilum IgG antibodies reported recurrence of symptoms of the disease at 3-4 months post-treatment. The co-infection may have influenced the intensity of the clinical manifestations of Lyme disease.

\section{CONCLUSIONS}

1. The presence of high concentrations of anti-C6VlsE IgG is associated with appearance of response to Borreliella spp. infection, which suggests that the parameter can be used in the diagnosis of the active form of borreliosis. The results support a need for further study to assess the individual relationship between anti-C6VlsE IgG and clinical image correlation. However, from a practical point of view, a marker of successful elimination of infection should indicate the effectiveness or failure of antibiotic therapy within a relatively short post-treatment period. The anti-C6VlsE IgG antibodies do not seem to satisfy this provision.

2. IP-10 may play a role in the assessment of the dynamics of the disease process in patients with Lyme disease relative to the treatment, but this requires research involving a larger group of patients.

\section{REFERENCES}

1. Bamm VV, Ko JT, Mainprize IL, et al. Lyme Disease Frontiers: Reconciling Borrelia Biology and Clinical Conundrums. Pathogens. 2019; 8(4): 299. https://doi.org/10.3390/pathogens8040299

2. National Institute for Health and Care Excellence. Lyme disease. NICE guideline (NG95). Published date: 11 April 2018, https://www.nice. org.uk/guidance/ng95/resources/lyme-disease-pdf-1837756839877 (access: 2020.10.01).

3. Pancewicz SA, Garlicki AM, Moniuszko-Malinowska A, et al. Diagnosis and treatment of tick-borne diseases recommendations of the Polish Society of Epidemiology and Infectious Diseases. Przegl Epidemiol. 2015; 69(2): 309-316.

4. Chmielewski T, Dunaj J, Gołąb E, et al. Diagnostyka laboratoryjna chorób odkleszczowych. Krajowa Izba Diagnostów Laboratoryjnych, Warszawa: Rekomendacje Grupy Roboczej 2014, 1-50. https://kidl.org. pl/get-file/150_05kleszcze-z-okladka.pdf (access: 2020.09.16).

5. Krzemień PJ. Role of VIsE/C6 antigen as a marker for early Lyme borreliosis diagnosis and monitoring the effectiveness of its treatment. Health Probl Civiliz. 2017; 11(2): 87-92. https://doi.org/10.5114/ hpc.2017.69023

6. Zajkowska JM, Kondrusik M, Pancewicz SA, et al. Comparison of test with antigen VlsE (C6) with tests with recombinant antigens in patients with Lyme borreliosis. Pol Merkur Lek. 2007; 23(134): 95-99.

7. Cinco M, Murgia R. Evaluation of the C6 enzyme-linked immunoadsorbent assay for the serodiagnosis of Lyme borreliosis in northeastern Italy. New Microbiol. 2006; 29(2): 139-141.

8. Marangoni A, Sambri V, Accardo S, et al. A Decrease in the Immunoglobulin G Antibody Response against the VlsE Protein of Borrelia burgdorferi Sensu Lato Correlates with the Resolution of Clinical Signs in Antibiotic-Treated Patients with Early Lyme Disease. Clin Vaccine Immunol. 2006; 13(4): 525-529. https://doi.org/10.1128/CVI.13.4.525529.2006

9. Fleming RV, Marques AR, Klempner MS, et al. Pre-treatment and post-treatment assessment of the $\mathrm{C}(6)$ test in patients with persistent symptoms and a history of Lyme borreliosis. Eur J Clin Microbiol Infect Dis. 2004; 23(8): 615-618. https://doi.org/10.1007/s10096-004-1163-Z 
10. Petnicki-Ocwieja T, Kern A. Mechanisms of Borrelia burgdorferi internalization and intracellular innate immune signaling. Frontiers in Cellular and Infection Microbiology 2014; 4(175): 1-7. https://doi. org/ 10.3389/fcimb.2014.00175

11. Petnicki-Ocwieja T, Chung E, Acosta DI, et al. TRIF mediates Toll-like receptor 2-dependent inflammatory responses to Borrelia burgdorferi. Infect Immun. 2013; 81: 402-410. https://doi.org/10.1128/IAI.00890-12

12. Baszczuk A, Kopczyński Z, Thielemann A, et al. Evaluation of concentrations of metalloproteinase 2 (MMP-2) and metalloproteinase 9 (MMP-9) in serum of patients with primary hypertension. Forum Zaburzeń Metabolicznych 2015; 6(2): 74-84.

13. Sulka KB, Strle K, Crowley JT, et al. Lyme Disease-Associated IgG4 autoantibodies correlate with synovial pathology in antibioticrefractory Lyme arthritis. Arthritis Rheumatol. 2018; 70(11): 1835-1846. https://doi.org/10.1002/art.40566

14. Strle K, Sulka KB, Pianta A, et al. T-Helper 17 cell cytokine responses in Lyme Disease correlate with Borrelia burgdorferi antibodies during early infection and with autoantibodies late in the illness in patients with antibiotic-refractory Lyme arthritis. CID. 2017; 64(7): 930-8 https://doi.org/10.1093/cid/cix002

15. Crowley JT, Strle K, Drobin EE, et al. Matrix metalloproteinase-10 is a target of $\mathrm{T}$ and $\mathrm{B}$ cell responses that correlate with synovial pathology in patients with antibiotic-refractory Lyme arthritis. J Autoimmun. 2016; 69: 24-37. https://doi.org/10.1016/j.jaut.2016.02.005

16. Philipp MT, Wormser GP, Marques AR, et al. A Decline in C6 antibody titer occurs in successfully treated patients with culture-confirmed early localized or early disseminated Lyme borreliosis. Clin Diagn Lab Immunol. 2005; 12(9): 1069-1074. https://doi.org/10.1128/ CDLI.12.9.1069-1074.2005

17. Pegalajar-Jurado A, Schriefer ME, Welch RJ, et al. Evaluation of Modified Two-Tiered Testing Algorithms for Lyme disease laboratory diagnosis using Well-Characterized Serum Samples. J Clin Microbiol. 2018; 56: e01943-17. https://doi.org/10.1128/JCM.01943-17

18. Zhao H, Dai X, Han X, et al. Borrelia burgdorferi basic membrane protein a initiates proinflammatory chemokine storm in THP 1-derived macrophages via the receptors TLR1 and TLR2. Biomedicine
\& Pharmacotherapy 2019; 115: 108874. https://doi.org/10.1016/j biopha.2019.108874

19. Aucott JN, Soloski MJ, Rebman AW, et al. CCL19 as a chemokine risk factor for Posttreatment Lyme Disease Syndrome: a prospective clinical cohort study. Clin Vaccine Immunol. 2016; 23(9): 757-766. https://doi. org/10.1128/CVI.00071-16

20. Steere AC, Strle F, Wormser GP. Lyme borreliosis. Nat Rev Dis Primers. 2016; 2: 16090. https://doi.org/10.1038/nrdp.2016.90

21. Liu M, Guo S, Hibbert JM, et al. CXCL10/IP-10 in infectious diseases pathogenesis and potential therapeutic implications. Cytokine Growth Factor Rev. 2011; 22(3): 121-130. https://doi.org/10.1016/j. cytogfr.2011.06.001

22. Fallahi P, Elia G, Bonatti A. Interferon- $\gamma$-induced protein 10 in Lyme disease. Clin Ter. 2017; 168(2): e146-150. https://doi.org/10.7417/ CT.2017.199

23. Codolo G, Bossi F, Durigutto P, et al. Orchestration of inflammation and adaptive immunity in Borrelia burgdorferi induced arthritis by neutrophil-activating protein A. Arthritis Rheum. 2013; 65: 1232-42. https://doi.org/10.1002/art.37875

24. Hoversten K, Bartlett MA. Diagnosis of a tick-borne coinfection in a patient with persistent symptoms following treatment for Lyme disease. BMJ Case Rep. 2018; 2018: bcr2018225342. https://doi.org/10.1136/ bcr-2018-225342

25. Velušček M, Blagus R, Cerar Kišek T. Antibiotic Use and LongTerm Outcome in Patients with Tick-Borne Encephalitis and CoInfection with Borrelia Burgdorferi Sensu Lato in Central Europe. A Retrospective Cohort Study. J Clin Med. 2019; 8(10): 1740. https://doi. org/10.3390/jcm8101740

26. Dunaj J, Moniuszko-Malinowska A, Swiecicka I, et al. Tick-borne infections and co-infections in patients with non-specific symptoms in Poland. Adv Med Sci. 2018; 63(1): 167-172. https://doi.org/10.1016/j. advms.2017.09.004

27. Moniuszko A, Dunaj J, Święcicka I, et al. Co-infections with Borrelia species, Anaplasma phagocytophilum and Babesia spp. in patients with tick-borne encephalitis. Eur J Clin Microbiol Infect Dis. 2014; 33(10): 1835-1841. https://doi.org/10.1007/s10096-014-2134-7 